\title{
Clinical case neonatal thrombosis of preterm newborn
}

\author{
Botagoz Abentaeva ${ }^{1}$, Bibigul Charipova ${ }^{1}$, Botagoz Aubakirova ${ }^{1}$
}

${ }^{\prime}$ the Neonatal Resuscitation and Intensive Care Unit, Corporate Foundation "UMC" National Science Center for Maternity and Childhood, Astana, Kazakhstan

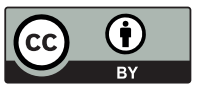

This work is licensed under

Creative Commons Attribution 4.0 International License

J CLIN MED KAZ 2017; 3(45 SUPPL 3):84-88

Автор для корреспонденции: Аубакирова Б.С., Национальный научный центр материнства и детства корпоративного фонда «UMC», Отделение реанимации новорожденных. Адрес: 010000, Туран 32, Астана, Казахстан. Телефон: 87086331504

Email: botaaubakir19@gmail.com

\section{ШАЛА ТУЫЛҒАН БАЛАДА НЕОНАТАЛДЫҚ ТРОМБОЗ \\ КЛИНИКАЛЫК ЖАҒДАЙЫ}

Абентаева Б.А. ${ }^{1}$, Чарипова Б.Т. ${ }^{1}$, Аубакирова Б.С. ${ }^{1}$

${ }^{1}$ Нәрестелер реанимациясының бөлімшесі , «UMC» корпоративтік қорының Ана мен бала ұлттық ғылыми орталығы, Астана, Қазақстан

\section{КЛИНИЧЕСКИЙ СЛУЧАЙ НЕОНАТАЛЬНОГО ТРОМБОЗА У НЕДОНОШЕННОГО РЕБЁНКА}

Абентаева Б.А. ${ }^{1}$, Чарипова Б.Т. ${ }^{1}$, Аубакирова Б.С. ${ }^{1}$

${ }^{1}$ Отделение реанимации новорожденных, Национальный научный центр материнства и детства корпоративного фонда «UMC», г. Астана, Казахстан

\section{Введение}

В имеющихся источниках литературы имеются описания случаев и серии случаев тромбозов и не было найдено больших исследований, сравнивающих различные виды терапии.

\section{Особенности гемостаза у новорожденных.}

К моменту рождения ребенка все факторы свертывающей и противосвертывающей систем находятся в состоянии динамического равновесия, но на ином, чем у взрослых, уровне, что обусловливает риск развития тромбозов $[5,6,9,10]$. Риск тромбоза еще усиливается, если присутствуют какие-либо факторы риска. Особенности гемостаза $[5,6,10]$ :

Соответствуют содержанию и активности у взрослых - V фактор, VIII фактор и количество тромбоцитов;

Соответствуют содержанию у взрослых, но отличаются структурой и функциональной активностью фетальные фибриноген и плазминоген;

Составляют от 30 до 50 процентов от содержания и активности у взрослых - II, VII, IX, X, XI, XII, XIII факторы, антитромбин III, протеины $\mathrm{C}$ и $\mathrm{S}$, максимальная амплитуда агрегации тромбоцитов;

Превышают содержание или активность у взрослых - фактор Виллебранда, уровень растворимых фибринмономерных комплексов (РФМК).

Сосудистый тромбоз - прижизненное образование сгустков крови в просвете кровеносных сосудов.

Выделяют три фактора, способствующих развитию тромбоза [10]:

1. стаз крови;

2. системный или локальный дисбаланс естественных про- и антикоагулянтов;

3. дисфункция сосудистого эндотелия.

В большинстве случаев, венозный тромбоз у детей развивается на фоне того или иного патологического процесса и, реже, спонтанно, без явных причин.

Состояния, повышающие риск тромбозов у детей [10]: течение тяжелой инфекции/сепсиса, системного воспалительного заболевания, наличие центрального венозного катетера, течение злокачественного заболевания и его терапия, пороки развития сосудов и сердца, травма, дегидратация, нефротический синдром, тромбофилия.

Тромбофилии (или повышенная склонность к тромбозам) представляют собой наследственные и приобретенные состояния, характеризующиеся чрезмерной склонностью организма к тромбообразованию в кровеносных сосудах.

Тромбообразование является нормальным по своей сути процессом, который препятствует избыточному истечению крови в местах повреждений сосудистой стенки. Однако в том случае, если тромботический процесс становится избыточным или развивается спонтанно и является самостоятельной причиной, он представляет собой патологический тромбоз.

Внутриутробный тромбоз: Патогенез внутриутробного тромбоза с развитием гангрены можно разделить на: тромбоз, возникший при внутриутробной компрессии и тромбоз и от тромбоэмболических явлений.

Компрессия (сжатие) обычно вызвано: аномалиями плода, его неправильным предлежанием с выпадением конечностей, маловодием, наличием амниотических перетяжек, обвитием пуповины. Тромбоэмболия может 
развиться в плаценте и эмболы, проходя через овальное отверстие, могут подать в артериальную систему, вызывая в основном некроз верхних конечностей. (рисунок 1,2).

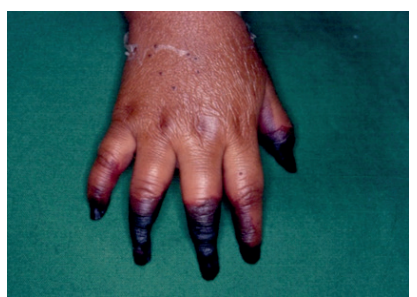

Рисунок 1

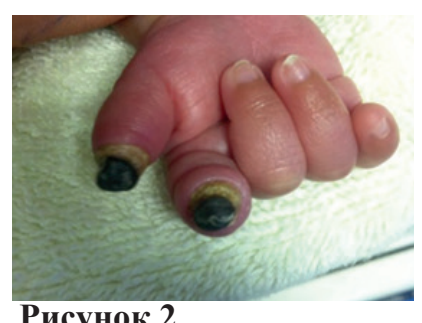

Рисунок 2
Внутриматочная ишемия плода, вызванная тромбозом или эмболией может быть связана с:

1. материнским диабетом,

2. преждевременными родами,

3. маловодием,

4. полицитемией,

5. фето-фетальной трансфузией.

6. По данным зарубежных источников известно, что[5,6,9]:

7. Новорожденные дети имеют повышенный риск развития тромбоза, потому что концентрация прокоагулянтов, антикоагулянтов и фибринолитических факторов в плазме отличаются от показателей у более старших детей и у взрослых.

8. Тромбоцитопения часто сопровождает тромбоз и является важным фактором в оценке риска тромбообразования.

9. Большинство венозных тромбов не имеют клинической симптоматики. Большинство из них связаны с установленным катетером. Клинически выраженный тромбоз нижней полой вены или верхней полой вены может клинически проявляться отеканием пораженной конечности.

10. Тромбоз портальной вены является осложнением катетеризации пупочной вены и развивается примерно у $1 \%$ новорожденных, несмотря на правильно установленные катетеры. Частота развития выше в случае если катетер расположен в зоне с низкой скоростью кровотока. Тромбоз портальной вены может привести к лобарной атрофии печени или к портальной гипертензии.

11. Тромбоз почечной вены составляет примерно $10 \%$ от числа венозных тромбозов у новорожденных и является самой частой формой тромбоза не связанного с сосудистым катетером. Тромбоз почечной вены чаще всего сопровождается гематоурией и тромбоцитопенией. Факторами риска по развитию данного состояния являются недоношенность, перинатальная асфиксия, дегидратация, сепсис, полицитемия, врожденные пороки сердца по цианотическому типу, сахарный диабет у матери и врожденные протромботические состояния.

12. Тромбоз правого предсердия связан с центральным венозным расположением катетера. Он может проявляться как новый шум, сердечная недостаточность, длительный сепсис, а также как неисправность катетера.

13. Артериальный тромбоз почти всегда связан с артериальными катетерами такими как пупочный и периферический артериальный катетер, которые обычно используются для определения показателей кровяного давления, газового состава крови или бедренной артерии, которую используют для сердечной катетеризации. Артериальный тромбоз связанный с катетаризацией пупочной артерии может быть бессимптомным или проявляться в виде ишемии, дисфункции органа в зависимости от расположения тромба.

14. Артериальный тромбоз, связанный с катетерами периферический артерий может проявляться в виде ослабления или исчезновения периферического пульса, снижения перфузии, увеличения времени наполнения капилляров, а также бледностью и прохладностью конечности. Выраженный тромбоз существующий на протяжении длительного периода времени может вызвать нарушения роста поврежденной конечности.

15. Диагноз тромбоза может быть заподозрен на основании факторов риска (например, наличие непроходимого катетера) и клинических симптомов и подтвержден инструментальными исследованиями. Ультразвуковое исследование используется в большинстве случаев, хотя его точность довольно ограничена при имеющемся установленном катетере.

Клинические проявления, позволяющие заподозрить диагноз тромбоза у детей:

- Отек или пастозность конечности, в том числе локально, в месте стояния катетера;

- Болевой синдром;

- Выраженность сосудистых коллатералей, особенно у детей с дефицитом подкожно-жировой клетчатки;

- Умеренная гипертермия конечности;

- Изменение окраски кожи;

- Явления асцита;

- Выпот в брюшной полости;

- Нарастающая гепатоспленомегалия;

- Гематурия, олиго/анурия при поражении сосудов почек;

- Нарастающая сердечно-легочная недостаточность, снижение сатурации по кислороду, боли в грудной клетке, кашель, кровохарканье при ТЭЛА.

Генетические факторы риска развития тромбозов $[8,9,10]$.

В литературе описаны случаи внутриутробного артериального тромбоза, обусловленного мутацией метилентетрагидрофолат редуктазы (MTHFR) и фактора V Лейдена.

Впервые генетическая причина патологических тромбозов - дефицит АТ III - была обнаружена в 1965 г. В 1981-1982 гг. выявлены тромбофилии, вызванные дефицитом Протеина С (PC) и Протеина S (PS). Затем была выявлена резистентность Фактора Va $(\Phi$ V) к активированному РС. Активированный РС ингибирует Фактор Va и Фактор VIIIa, замедляя тем самым выработку тромбина. Вскоре эта аномалия была идентифицирована как замещение единичной аминокислоты в одном из субстратов $\mathrm{PC}$ - Фактор V; позднее она получила название Ф V Лейден. ФV-L-мутация может обусловливать повторяющиеся выкидыши вследствие тромбоза плацентарных сосудов.

Вцеломрискразвитиятромбоэмболииугетерозиготных 
носителей этой мутации увеличен семикратно по сравнению с нормой; для гомозиготных носителей риск развития тромботических заболеваний возрастает в 80 раз.

Избыточная активность протромбина (Фактора II). Протромбин - предшественник тромбина, конечного продукта каскада коагуляции, обладающий, помимо прокоагулянтнй, также антикоагулянтной и антифибринолитической активностью.

Любые нарушения функциональной активности протромбина влекут за собой множественные сдвиги в гемостатическом равновесии. Мутация гена протромбина (протромбин G20210A) встречается главным образом среди белого населения, причем наиболее часто он распространен в Испании. Общая его распространенность в различных регионах составляет от 0,7 до 6,5\%. Протромбин G20210A повышаетрискразвитиятромбозауносителяприблизительно втрое по сравнению с нормой. При этом как генетическая аномалия, так и повышенная протромбиновая активность в равной мере являются маркерами предрасположенности к тромботическому заболеванию.

ДефицитпротеинаС. Дефицитпротеина С (РС)встречается реже, чем $\Phi \mathrm{V}$ Лейден или мутация гена протромбина. Его распространенность среди белого населения составляет 0,2-0,5\%. Этот протромбогенный дефект наследуется по аутосомно-доминантному типу и нередко ассоциируется с семейным венозным тромбозом.Ген РС расположен на хромосоме 2 и тесно связан с геном Ф IX. Прямая функция этого белка - инактивация факторов свертывания Va и VIIIa. Оба эти фактора необходимы, в конечном счете, для адекватной выработки тромбина; их избыток ведет к стимуляции его выработки сверх нормы.Дефицит РС (количественный или функциональный) в итоге означает повышенную генерацию тромбина и тромбогенность. Особенность этого дефекта состоит в том, что он может иметь клинические проявления уже в младенчестве. У гомозиготных носителей это может быть фульминантный (молниеносный), тромбоз, у гетерозиготных - повышенный риск варфарин-индуцированного некроза кожи (в более позднем возрасте).

При беременности дефицит РС может быть причиной тромбоза глубоких вен, преэклампсии, ограничения внутриматочного роста и рецидивирующих выкидышей.

Проведенные в Нидерландах и США исследования показали, что дефицит РС означает 8-10-кратное возрастание риска развития тромбоза и что в возрасте 40 лет у более $50 \%$ носителей имеются случаи тромботических заболеваний.

Приблизительно у $60 \%$ носителей развивается рецидивирующий венозный тромбоз и приблизительно у 40\% имеются признаки ТЭЛА.

При этом риск развития тромбоза в разных семьях очень неодинаков. В одних семьях 75\% носителей имеют случаи тромботических заболеваний, в других - частота тромбоза гораздо ниже.

Дефицит протеина S. Протеин S (PS) - кофактор PC, способствующий расщеплению последним $\Phi$ Va и $\Phi$ VIIIa. Этот белок кодируется двумя гомологичными генами, располагающимися на хромосоме 3. Дефицит PS наследуется по аутосомно-доминантному типу и имеет приблизительно ту же распространенность, что и дефицит РС. Клинические проявления этого дефекта также аналогичны дефициту РС и АT III. У гетерозиготных носителей дефицита PS развивается тромбоз при уровне его функциональной активности $15-50 \%$ от нормы. По данным ряда опубликованных исследований, вероятность развития тромбоза в течение жизни у носителей дефицита PS в 8,5 раза выше, чем у лиц, не имеющих этого дефекта. Клинические проявления у гетерозиготных носителей, как правило, имеют место в зрелом возрасте. В сочетании с другими тромбогенными дефектами или в гомозиготной форме дефицит PS обычно проявляется у новорожденных в виде фульминантного (молниеносного) тромбоза.

Дефицит антитромбина III, как и все описанные выше генетические дефекты, наследуется по аутосомнодоминантному типу и поэтому может присутствовать как у мужчин, так и у женщин. Известно несколько типов дефицита АT III.

Тип I - сниженный биосинтез биологически нормальных молекул. Этот тип характеризуется снижением как антигенной, так и функциональной АТ-активности в крови носителя. У гетерозиготных носителей обе величины бывают снижены приблизительно на 50\%. В основе типа I дефицита АТ могут лежать свыше 80 мутаций.

Тип II характеризуется внутримолекулярными дефектами, т.е. нарушениями структуры молекул белка АТ. Проявляется он в том, что при нормальной иммунологической активности функциональная активность AT резко снижена, что ведет к риску развития тромбоза.

Для типа III характерны нормальные уровни АT (функциональный и антигенный) при нарушенном взаимодействии с гепарином, без которого АТ выполняет свою функцию крайне медленно.

Для детского возраста клинические проявления дефекта нехарактерны. Наиболее распространенной аномалией АТ является тип II. Его распространенность в Шотландии составила 1:630 при той же величине общей распространенности дефекта по всем типам.

Распространенность других типов дефекта весьма мала. При разных видах наследственной тромбофилии вероятность тромботического заболевания в течение жизни при дефиците PS в 8,5 раза выше, чем в норме (при отсутствии дефекта), при типе I АТ-дефицита - в 8,1 раза, при дефиците РС - в 7,3 раза, при Ф V Лейден - в 2,2 раза.

Дисфибриногенемия (функциональный дефицит фибриногена) также может быть причиной предрасположенности к формированию тромбов.Механизм тромбофилии, по всей видимости, состоит в нарушении фибрин-опосредованной активации плазминогена (точнее, усиления его активации тканевым плазминогенактивирующим фактором).

В основе дисфункции, как правило, лежат мутации, число которых, согласно одной из последних баз данных, достигает 330. Тип наследования, за редким исключением, аутосомно-доминантный. В большинстве случаев дисфибриногенемия протекает бессимптомно. Однако иногда бывают случаи геморрагического диатеза или тромбофилии; возможно сочетание кровотечений и тромбоэмболии.

Распространенность врожденной дисфибриногенемии среди больных с венозными тромбозами в анамнезе, по последним данным, составляет $0,8 \%$.

Гипергомоцистеинемия. Гипергомоцистеинемия в последние годы признана независимым фактором риска развития тромбоза. Этот дефект, который может быть как врожденным, так и приобретенным, в умеренной форме встречается часто - от 5 до $7 \%$ случаев в общей 
популяции. Механизм тромбогенного действия избытка гомоцистеина пока не вполне ясен. Наиболее характерным генетическим дефектом, следствием которого является накопление гомоцистеина в крови, считается мутация, обусловливающая выработку термолабильного варианта МТГФР со сниженной активностью. Этот дефект выявляется у 1,4-15\% белого населения.Сниженная активность МТГФР может привести к замедлению метилирования гомоцистеина с его последующим накоплением. В то же время сниженная активность этого фермента означает недостаточную выработку окиси азота - важнейшего вазодилататора. Это, в свою очередь, ведет к сужению кровеносных сосудов c нарушением целостности эндотелия и последующим тромбированием.

\section{Избыточная активность Ф VIII и Ф XI, дефицит Ф XII}

Имеются сведения о семейной предрасположенности избыточной активности Ф VIII, а также о ее взаимосвязи с группой крови и содержанием в крови Ф Виллебранда.

Кроме того, имеются убедительные данные в пользу возрастания тромботического риска при повышенной активности Ф XI, активирующего Ф IX и стимулирующего, в ряду прочих факторов, выработку тромбина.Дефицит Ф XII может способствовать тромбозу и быть наследственным. Хотя роль этого дефекта в стимуляции избыточного формирования тромбов невелика, но сниженная фибринолитическая активность создает реальную угрозу тромбозов и должна считаться фактором риска.

Липопротеин (LP)a - наследственный фактор риска развития тромбоэмболии. Lp(a) ингибирует связывание плазминогена с поверхностью клетки, уменьшая тем самым выработку плазмина и растворение фибриновых сгустков. Кроме того, Lp(a) инактивирует ингибитор пути тканевого фактора (внешнего пути активации гемостаза) - главный эндогенный регулятор этого пути свертывания. При повышенном уровне Lp(a) (>300 мг/л) риск тромбозов и венозной тромбоэмболии возрастает приблизительно вдвое. Риск тромбоэмболического события у детей с повышенным уровнем Lp (а) составляет 7,2.

\section{Описание клинического случая}

Новорожденный поступил в отделении реанимации с диагнозом: Респираторный дистресс-синдром тяжелой степени. Крайняя незрелость. Недоношенность 27 недель. ЭНМТ при рождении.

Антропометрические данные: масса тела - 850грамм, длиной тела - 36см, окружность головы $-26 \mathrm{~cm}$, окружность груди - 20см. Оценка по шкале Апгар - 5/6 баллов.

С момента поступления в ОРИТН состояние ребенка оценивалось как крайне тяжелое, нестабильное за счет респираторных, гемодинамических нарушений на фоне глубокой морфофункциональной незрелости, ЭНМТ при рождении. Определен серьезный прогноз для жизни с высокой долей неблагоприятного исхода, на основании крайне отягощенного акушерского анамнеза: преэклампсия тяжёлой степени, прогрессирующая артериальная гипертензия у матери, несмотря на неоднократное лечение гипотензивными, антикоагулянтными препаратами. Нарушение маточно-плодово-плацентарного кровотока 3 степени. Компенсированное нарушение гемодинамики плода 1 степени, обусловило преждевременное рождение крайне незрелого ребенка с экстремально низкой массой тела с тяжелыми респираторными и гемодинамическими нарушениями. О незрелости ребенка свидетельствовала также сохраняющаяся тяжесть респираторных и гемодинамических нарушений, несмотря на проведенный комплекс лечебных мероприятий по стабилизации общего состояния (сурфактант-терапия, кардиотоническая терапия, ИВЛ). Начиная с момента рождения неоднократно проводились беседы с родственниками. В частности, разъяснялась исходная тяжесть состояния ребенка, неблагоприятный фон со стороны матери, высокий риск возникновения различных осложнений. В последующем, состояние ребенка сохранялось тяжелым, нестабильным. Неоднократно проводились осмотры узких специалистов; консилиумы с определением тактики ведения и лечения пациента. Но, несмотря на проводимую терапию, состояние ребенка сохранялось тяжелым, у ребенка определенно сформировалась высокая зависимость от ИВЛ с высокой концентрацией кислорода, в пределах от 30 до 55\%, что указывает на высокий риск раннего развития БЛД, на фоне затяжного течения пневмонии.

В случае ведения пациента применение общепринятых современных стандартов лечения недоношенных новорожденных показало свою эффективность, по сколько в последующем ребенок был экстубирован через 3 суток, переведен на неинвазиную вентиляцию СРАР с переводом на самостоятельное дыхание, на дальнейшее выхаживание в отделение неонатологии, без развития тяжелых последствий для легких. Также ребенку был проведен курс медикаментозной коррекции открытого артериального протока (ОАП) препаратом «Педеа», без осложнений.

На 25-е сутки жизни в месте стояния катетера было отмечено нарушение кровотока, кожа правой кисти была бледной, прохладной на ощупь, движения в кисти не нарушены, пульсация снижена, отмечается незначительная пастозность - ангиоспазм сосудов правой кисти. Проконсультирован сосудистым хирургом, детским хирургом. Проведены следующие мероприятия: введение гепарина внутривенно в дозе 75 ЕД/кг массы тела внутривенно болюсно в течение 10 мин и далее поддерживающая доза 28 ЕД/кг/ч, инфузия алпрестила 0,01мкг/кг/мин, внутривенно, повязки с гепарином. Ультразвуковое доплеровское исследование сосудов правой кисти было не информативным. В дальнейшем сформировался тромбоз сосудов правой кисти, с переходом в некроз кисти.

На 33 сутки жизни проведена операция: Ампутация средней трети правого предплечья, правой кисти.

В динамике состояние было с положительной динамикой: на 48 сутки жизни переведен на II этап выхаживания недоношенных детей. На 130 сутки жизни выписан домой.

\section{Обсуждение}

Столь скоротечное развитие тромбоза сосудов руки ребенка, возможно, объясняется наличием врожденного дефекта в системе гемостаза. К настоящему времени открыто множество генетических мутаций, обусловливающих дисфункцию факторов гемостаза, антикоагуляции и фибринолиза и объясняющих склонность больных к тому или иному виду тромбофилии в аспекте риска тромбоза. Имеется более 500 генов-кандидатов, мутации в которых могут создавать предрасположенность к венозному тромбозу $[1,2]$.

Однако, в данном случае возможно полагать, что причиной дефекта является гипергомоцистеинемия, которая в последние годы признана независимым фактором риска 
развития тромбоза. Механизм тромбогенного действия избытка гомоцистеина пока не вполне ясен. Наиболее характерным генетическим дефектом, следствием которого является накопление гомоцистеина в крови, считается мутация, обусловливающая выработку термолабильного варианта МТГФР со сниженной активностью. Сниженная активность этого фермента означает недостаточную выработку окиси азота - важнейшего вазодилататора. Это, в свою очередь, ведет к сужению кровеносных сосудов с нарушением целостности эндотелия и последующим тромбированием $[3,4]$. Этим дефектом можно объяснить развитие и у матери ребенка преэклампсии тяжелой степени с рефрактерной гипертензией, которая даже при назначении 3-х гипотензивных препаратов не поддавалась лечению и явилась причиной оперативного родоразрешения женщины на раннем сроке беременности.
Нельзя исключить и сочетанный дефицит РС и PS, который приводит к фульминантному (молниеносному) тромбозу. При беременности этот дефект может быть причиной тромбоза глубоких вен, преэклампсии, ограничения внутриматочного роста и рецидивирующих выкидышей.

\section{Выводы}

Таким образом, наличие множества генетических мутаций, обусловливающих дисфункцию факторов гемостаза, не позволяет выявить точную причину возникновения тромбоза, современные технологии, осуществляемые в перинатальных центрах, увеличивают выживаемость детей в неонатальном периоде и вместе с тем это увеличивает количество инвалидизирующих осложнений, в частности тромбозов сосудов.

\section{Литература:}

1. Buller H.R., Sohne M., Middeldorp S. Treatment of venous thromboembolism. J.Thromb. Haem. 2005; 3:1554-1560;

2. Wells P.S. Integrated strategies for the diagnosis of venous thromboembolism. J.Thromb.Haemost. 2007; 5 (1):41-50.

3. Khan S., Dickerman J.D. Hereditary thrombophilia. Thromb. J. 2006; 4: 15-38.

4. Vasil'ev S.A., Vinogradov V.L. Rol' nasledstvennosti v razvitii trombozov (The role of heredity in the development of thrombosis) [in Russian]. Tromboz, gemostaz i reologija. 2007; 3:32-40.

5. Monagle P, Chalmers E, Chan A, et al. Antithrombotic therapy in neonates andchildren: American College of Chest Physicians Evidence-Based Clinical Practice Guidelines (8th Edition). Chest. 2008; 133:887.

6. Hirsh J, Bauer KA, Donati MB, et al. Parenteral anticoagulants: American College of Chest Physicians Evidence-Based Clinical Practice Guidelines (8thEdition). Chest. 2008; 133:141.

7. Tanvig M, Jørgensen J. S., Nybo M, Zachariassen G. Intrauterine Extremity Gangrene and Cerebral Infarction at Term: A Case Report. Case Reports in Pediatrics. 2011, Article ID 363517, 4 p.

8. Armstrong A. P. , Page R. E. Intrauterine vascular deficiency of the upper limb. Journal of Hand Surgery. 1997; 22(5):607611.

9. Veldman A, Marcel F, Michel-Behnke I. Thrombosis in the critically ill neonate: incidence, diagnosis, and management. Vasc Health Risk Manag. 2008; 4(6): 1337-1348.

10. Chuvakova T.K. Jeffektivnye perinatal'nye tehnologii uhoda i medicinskoj pomoshhi novorozhdennym detjam (Effective perinatal care and medical care technologies for newborn children) [in Russian]. Astana; 2015. 290-300 p. 